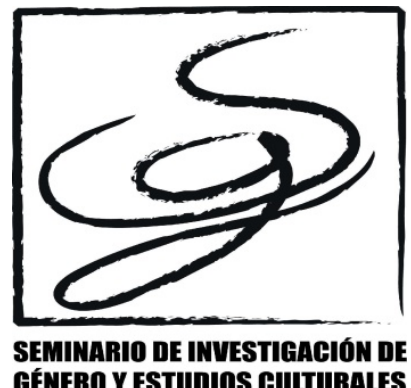

\title{
Dacia Maraini: hijos abusados y madres silenciadas
}

\section{Dacia Maraini: Abused children and silenced mothers \\ Begoña Gonzáles Rodríguez \\ Universidad de Sevilla \\ gr2be@hotmail.com}

\author{
Fecha de recepción: 26/05/2020 Fecha de evaluación: 01/09/2020 \\ Fecha de aceptación: 16/11/2019
}

\begin{abstract}
:
Dacia Maraini has moved to her works the harsh reality of many children who live trapped in the networks of men who comment on them sexual abuse and with whom they share their day to day. Indirectly, the mothers of these children are also prisoners of such violence by their partners. This work aims to analyze through four stories of Dacia Maraini, the role of mothers in the sexual abuse of their children. Whether they are accomplice, or they confront abusers standing up for their children, mothers carry the burden of guilt, which sometimes means the destruction of their own lives.
\end{abstract}

Key-words: Dacia Maraini; mothers; children; harassment; sexual abuse; violence; women

\section{Resumen:}

Dacia Maraini ha trasladado a sus obras la cruda realidad de muchos niños que viven atrapados en las redes de hombres que cometen sobre ellos abusos sexuales y con quienes comparten su día a día. De manera indirecta las madres de esos niños también son prisioneras de esa violencia por parte de sus parejas. Este trabajo pretende analizar a través de cuatro relatos de Dacia Maraini, el papel de las madres ante el abuso sexual de sus hijos. Tanto si son cómplices, como si se enfrentan a los abusadores, poniéndose de parte de los hijos, las madres cargan con el peso de la culpa, lo que supone a veces la destrucción de sus propias vidas.

Palabras clave: Dacia Maraini; madres; niños; acoso; abuso sexual; violencia; mujeres 


\section{Introducción}

La infancia es la etapa de la vida que suele asociarse a la ternura, la felicidad, la diversión o las despreocupaciones, junto con otros tópicos agradables. Es el momento en el que uno está más unido a sus familiares, empieza a hacer amigos y vive ajeno a las adversidades que más tarde se conocen en la vida adulta. La infancia como paraíso perdido y lugar edénico ha sido tematizado en la obra de muchos escritores y escritoras. Sin embargo a veces, lejos de ser un período idílico de la vida, puede convertirse en un infierno para quienes sufren abusos sexuales por parte de la figura paterna. Un tema tabú que solo recientemente ha sido representado en literatura.

El abuso sexual infantil (ASI), la mayoría de las veces tiene su origen en el entorno familiar (Quintero, 2014; Cortés, 2014; Guzmán, 2014). Generalmente, se produce por parte de personas que pasan mucho tiempo con los niños, y tienen la ocasión de que los abusos puedan darse con mayor frecuencia y permanezcan ocultos durante un largo período de tiempo. Gracias a la asimetría de edad y, a su posición de poder, los adultos pueden manipular fácilmente a los menores (Azaola, 2006). Como sostiene Florence Rush:

the reason why [the molester] seeks out a child as a sexual partner is because a child, more than a woman, has less experience, less physical strength, is more trusting of and dependent upon adults and therefore can be more easily coerced, seduced, lured or forced (Rush,1980: 2)

La escritora italiana Dacia Maraini, en su incansable lucha por denunciar la violencia contra las mujeres y los niños, afronta muchas veces el tema de la violencia intrafamiliar. Niñas y niños son protagonistas de relatos en los que sufren violaciones sexuales, ejercidas por quien ostenta el papel de padre. Así lo explica en su estudio Susan Amatangelo (2017):

Maraini afronta el argumento de la violencia en los niños con la misma franqueza con la que escribe de la experiencia femenina. Sus historias de víctimas, niñas, en particular, amplían el impacto de su discurso sobre la violencia contra las mujeres (Amantangelo, 2017: 215).

Lo que pretende la autora es dar visibilidad a una violencia desgarradora que lleva siglos silenciándose. Busca que la sociedad reaccione y se luche por conseguir un futuro con espacios seguros en los que los niños no tengan que pasar por el dolor de la violencia (Harble \& Popović, 2015).

Este artículo tiene como objetivo analizar la posición de las madres de niños y niñas abusados sexualmente en dos novelas: Bagheria (1993), Voci (1994), y dos relatos: "la esposa segreta" perteneciente a la colección Amore rubato (2012) y "Ha undici anni, si chiama Tano" que forma parte de la colección de Buio (1999). Las madres adoptan dos 
posturas: por un lado, la del desconocimiento absoluto del abuso, por otro, todo lo contrario, lo conocen y no ponen medios para que se termine.

\section{El papel de las madres en la violencia familiar}

Sostiene Irene Intebi (2001) que la reacción de las madres ante los abusos sexuales de sus hijos es crucial en la evolución del trauma. Explica que hay madres que suponen un apoyo incondicional tras descubrir su sufrimiento. Mientras que otras, especialmente cuando el abusador es su pareja o padre de los niños, reaccionan rechazando la versión de los niños y, respaldando al adulto.

Para Dacia Maraini la relación madre-hija es el lazo afectivo del que nace la creatividad, la complicidad e incluso la libertad. La escritora parte de su propia experiencia personal y explica en La nave per Kobe. Diari giapponesi di mia madre (2001) la importancia del símbolo materno por el amor que subyace en esa figura. La unión con la madre sirve de ayuda en la lucha para cambiar el destino de las mujeres y alcanzar una posición independiente en un mundo dirigido por hombres (Ivančić, 2016). Sin embargo, las relaciones entre las madres y sus hijas e hijos en su narrativa se muestran llenas de conflictos afectivos y psicológicos, para reflejar en una versión realista, las difíciles relaciones que se dan en el interior de las familiares, en las que se aprecia la violencia estructural contra las mujeres. El objetivo de Maraini es denunciar la violencia contra las personas más vulnerables: las mujeres y los niños. Como sostiene Michelangelo La Luna (2015), Maraini en lo que respecta a todos los tipos de violencia que tocan la infancia, más allá de la cuestión femenina, reclama una revolución social y cultural profunda con el fin de considerar al otro como sujeto de derechos fundamentales. En la misma línea Harble y Popović, (2015), sostienen que estos relatos pretenden despertar a la sociedad y "contribuir a crear un futuro en el que los niños no tengan que conocer la devastación causada por la violencia" (Harble \& Popović, 2015: 25)

La madre es un personaje muy importante y complicado dentro de la narrativa de Dacia Maraini. Se presentan como una "problemática" (Gabriele, 2004), con actitudes indiferentes o gobernadas por sus maridos Picchietti (2002) señala que la figura materna tiene una fuerza y es fundamental para el desarrollo subjetivo y social de los hijos, especialmente de las hijas.

En este trabajo, analizamos cuatro tipos de madres. En Bagheria, una de sus obras autobiográficas, Maraini habla de las del pueblo en el que pasó su niñez. No se decanta por ninguna en particular, sino que da una visión de conjunto del papel reducido que la sociedad del sur les asigna. Maraini denuncia a través de las madres los abusos sexuales que los padres cometían contra las hijas y de los que ellas eran conscientes. Secretos a voces de una sociedad hipócrita, que proclama ciertos valores morales que solo tienen validez para las mujeres y no implican de ningún modo a los hombres que pueden ejercer la violencia a su antojo. Las 
mujeres de la familia, hijas y madres, quedan obligadas al código del silencio y del encubrimiento para mantener el buen nombre de la familia.

En el relato de "Ha undici anni, si chiama Tano", Giuseppina Bacalone es la madre de una numerosa familia de siete miembros que defiende prácticamente en todo momento a su esposo, acusado por su hijo Tano de abusar de él y de todos sus hermanos. Una madre atemorizada que solo reconocerá las atrocidades de su esposo cuando se sienta segura de que él no podrá hacerle nada.

En Voci, Augusta Bari es la madre de Angela y Ludovica. Se trata de una mujer frívola que también es consciente de los abusos, pero que manifiesta poco afecto hacia sus hijas, que tuvieron una infancia marcada por haber sido abusadas por su padrastro.

Carmelina, la madre presente en el relato "La sposa segreta", es una mujer que, tras quedarse viuda con sus dos hijas pequeñas, encuentra de nuevo el amor. Deposita su confianza en un hombre aparentemente bondadoso que a sus espaldas violaba a sus hijas cuando ella se iba de viaje por motivos laborales. Tras descubrir el abuso, reaccionará y se pondrá de parte de las hijas.

\section{Madres silenciosas y silenciadas}

Dacia Maraini retrata en Bagheria la situación en la que vivían las mujeres en un pueblo de la Italia meridional, en el que estaban privadas de cualquier libertad e independencia. Este fenómeno todavía sucede en la actualidad, donde predomina una sociedad anclada en las costumbres rurales y patriarcales, donde el honor de la familia está por encima del bienestar físico o mental de sus miembros. Vanessa Leonardi (2007) habla de la figura del "padre padrone", que se repite en muchos personajes masculinos a lo largo de las obras de Maraini y que es la que predomina en el pueblo de Bagheria, en el que era vox populi que en algunas familias los padres abusaban de sus hijas:

Precisamente en Bagheria, había dos casos evidentes
que todos conocíamos y que nunca llegarían a ser
denunciados. Un padre había tenido un niño de su
propia hija. [...] Otro padre, en una de aquellas casas
sin ventanas que daban a los callejones de la parte
vieja del pueblo, había abusado de la hija cuando tenía
seis años. También bajo los ojos ciegos de su mujer. Y
había continuado abusando de ella, como por un
sacrosanto derecho, año tras año (Maraini, 2004: 147).

En Sicilia prevalece el sentimiento de moralidad afectiva y sexual inculcado por la iglesia, el autoritarismo del padre con respecto a las madres y los hijos, la disciplina y arbitrariedad en las relaciones entre padres e hijos y la destacada subordinación femenina (Galasso, 1983). La misma Maraini, cuando fue a vivir a Bagheria con su familia, conoció personalmente la realidad Siciliana como recuerda en una entrevista: "Cinco años en Palermo me hicieron conocer por primera vez la represión sexual y psicológica sobre la mujeres" (Weinberg, 1993) 
Explica Maraini que era algo habitual en los años treinta, y nadie se atrevía a denunciarlo, puesto que se consideraba normal. La mujer, por ley, pertenecía al padre y después al marido. En un contexto social en el que el divorcio no era posible y la separación del marido suponía la pérdida de la tutela de los hijos, la fuente de sustentamiento económico y la muerte social para las mujeres.

Con esta obra la escritora deja claro que el padre como cabeza de familia tenía el poder de control sobre la esposa, económica y socialmente dependiente de él. En lo que respecta a las hijas, los padres también las consideran de su propiedad, encontrándose respaldados por la moralidad que fomentaba la Iglesia (Bellesia, 2000).

La esposa y las hijas deben obediencia al marido y padre, quien tiene el poder supremo sobre las mujeres de su familia. La esposa, en su papel de madre, debe aceptar el abuso que su esposo ejerza sobre sus hijas. Ese es el motivo por el cual, en los casos de violaciones en Bagheria, la madre es consciente de ellas, pero no hace nada para remediarlas, puesto que no dispone legalmente de ningún instrumento para poder acabar con ellas. La figura del padre goza en la sociedad siciliana de toda credibilidad y prestigio, mientras que la figura de la madre está relegada al ámbito privado de la casa y la familia, sin ningún apoyo externo.

En Buio, Tano, el protagonista del relato, es un niño de once años que denuncia en repetidas ocasiones ante la policía que su padre abusa de él desde los siete años. Además, añade, que esos episodios de violencia también los han sufrido Clementina y Rosario, sus hermanos mayores. A priori, en comisaría no tienen en cuenta su acusación. Consideran que se debe a un momento de rabia puntual. De todos modos, la obstinación del niño hace que se inicie una larga investigación, puesto que como dice la inspectora: "Recuerde que el ochenta por ciento de los abusos sexuales tienen lugar en la familia" (Maraini, 2018: 98).

Primero, declara el padre negando rotundamente los hechos, dice que este le odia porque tiene episodios de impertinencia típicos de su edad y por ese motivo ha querido calumniarlo en señal de rebeldía contra él. Seguidamente, las primeras declaraciones de la madre definen al padre como un hombre afectuoso con sus hijos, un marido excelente y comprometido con su familia: "Él es cariñoso, quiere mucho a sus hijos, es un buen padre, se lo digo yo, un padre buenísimo" (Maraini, 2018: 99).

Los asistentes sociales que se ocupan del caso también consideran convincente el discurso del hombre, lo retratan como un padre de familia normal y bueno con sus hijos, por lo tanto el testimonio de Tano no tiene credibilidad para ellos. Esto deja ver una vez más, lo arraigado que está el sistema patriarcal en nuestra sociedad, puesto que los servicios sociales confían en la palabra del hombre por el simple hecho de serlo, sin darle el beneficio de la duda al menor ni ahondar más en el problema, poniendo de manifiesto la ideología patriarcal que legitima el poder y la autoridad del marido sobre la mujer en el matrimonio o en la pareja (Millet, 1969). Las palabras del marido no son puestas en entredicho porque, como sostiene Bourdieu (1985), los discursos no son únicamente signos 
destinados a ser comprendidos o descifrados, son también signos de autoridad destinados a ser creídos y obedecidos.

Clementina, hermana mayor de Tano, aporta la primera prueba de que la madre es sabedora de los abusos: "Hace dos años usted afirma que su padre Bacalone Luigi, comenzó a ponerle las manos encima cuando tenía cinco años. Escondiéndose de su madre, que una vez los pilló e hizo como si no hubiera visto nada" (Maraini, 2018: 102)

Los hermanos insisten en que la madre no se atreve a denunciar a su padre por miedo: "Tenía miedo. También mama tiene miedo" (Maraini, 2018: 121). La madre, sometida y sin fuerzas para imponerse al marido, es una imagen de la maternidad deteriorada y su despersonificación se aprecia en el hecho de que no tiene casi voz en el relato. Incluso la comisaria nos proporciona una imagen perturbada y animalizada de ella: "la madre se mueve en aquella casa como una rata asustada. A mí me parece una neurótica" (Maraini, 2018:123).

Solo cuando este admite sus culpas y es encarcelado la mujer acepta formalizar la denuncia, acción que deja en evidencia que el padre no solo ejercía violencia sexual sobre los hijos, sino también una tremenda violencia psicológica sobre su esposa, paralizada por el terror. Plantea María López Vigil (2005) que muchas mujeres, como la madre de Tano, se mantienen de parte del agresor por miedo. Sus hijos sostenían que ella era consciente del incesto que cometía su esposo, pero no se atrevía a abrir la boca. La mujer restaba importancia a los hechos, simplificaba la responsabilidad del abusador y lo protegía.

Como Plantea Ngozi (2015) a las mujeres se les enseña a callar, a sentir vergüenza y a jamás expresar lo que piensan. Esta situación se hace más grande cuando la mujer no tiene independencia económica, como es el caso de clementina. Además cree fielmente en la consideración tradicional de que el matrimonio es para toda la vida, el hombre es quien reina en esa unidad familiar y ella simplemente acata órdenes de forma automática, convirtiéndose en un ser sin capacidad de raciocinio. Aunque la mujer quisiera, el imaginario social en el que ha sido educada le ha enseñado a callar ante su marido, ese ser que para ella es superior y por lo tanto en el relato no vemos una intervención suya que directamente se enfrente a su marido-verdugo.

Respaldando la versión de la hija, que afirmaba que el padre abusaba de ella bajo la mirada materna, la mujer acaba aceptándolo. Considera que es algo "normal", que el abuso se produjera contra la hija por ser mujer, pero aun así sigue defendiendo la virilidad de su marido, lo que equivale también a defender, en cierto sentido, su imagen ante los demás: "No le gustaron nunca los varones, a él, ¿cómo podía imaginar que les ponía la mano encima a nuestros hijos? A Clementina todavía, pero a los hijos varones..." (Maraini, 2018: 133).

Este concepto de la masculinidad a ultranza también aparece en la declaración que el padre hace, reflejando su pensamiento homofóbico, muy presente en el sistema patriarcal, y la obsesión masculina por mostrar su virilidad ante el temor de ser considerado feminizado $u$ homosexual: 
Yo con los varones nunca he tenido nada. Yo no voy con varones, comisaria. Estoy felizmente casado. Con la niña algo ha pasado, si, lo admito, porque lo quería ella, pero los varones, ¿Por qué los iba a tocar? ¡Ni que yo fuera un invertido! (Maraini, 2018: 125).

En Voci Dacia Maraini presenta a una madre prepotente y poco afectuosa con sus dos hijas, que también fueron abusadas por su padrastro. Ambas crecieron con problemas de relaciones sociales. Ludovica, sufrió problemas psiquiátricos graves y Angela desarrolló una relación enfermiza y perversa con el abusador que la condujo a la muerte. Ludovica es quien explica en la historia que su madre era consciente de las prácticas sexuales a las que las sometía el padrastro, incluso las animaba en cierto modo: "Mi madre me hizo entender que aquel era el sacrificio necesario para tenerlo en la familia, para mantener su posición y su amabilidad" (Maraini, 2017: 249).

En las tres narraciones analizadas se observa que la familia, como explica Casares (2008), sigue una estructura patriarcal tradicional, en la que las mujeres están subordinadas a sus cónyuges y donde "la imagen de amor y felicidad se contradice con la violencia y crimen sexual que ocurre en su interior" (Casares, 2008: 5).

El silencio materno que aparece en las tres obras, a priori, parece reflejar su connivencia con el abusador, pero un análisis más profundo revela que la madre también es una víctima de la violencia que este ejerce en la familia dentro de un contexto más general tratándose de un sistema patriarcal, que denigra a las mujeres y les inculca la obediencia y la sumisión a la figura masculina. Maraini denuncia en su novela Un clandestino a bordo, la complicidad de una sociedad que promueve en todas las representaciones la figura de la madre como ser vacío de subjetividad propia y silencioso que se pliega a los deseos de los demás (Maraini, 1996). La violencia simbólica que se ejerce sobre las madres, las lleva a compartir el mismo sistema de creencias que sus parejas, por ello no intervienen en sus acciones, se limitan a respaldarlos, aunque eso conlleve la destrucción emocional de los hijos y de ellas mismas, en muchos casos.

Ese silencio de las madres podría asociarse a la noción de encerrona trágica ${ }^{1}$, pues necesitan del marido para poder seguir siendo sujetos sociales y cubrir sus necesidades, aunque lo que reciban a cambio sea humillación, desprecio, miedo y aceptación de la posesión

\footnotetext{
${ }^{1}$ Este concepto, según explica Ulloa, se refiere a "cada vez que alguien, para dejar de sufrir o para cubrir sus necesidades elementales de alimentos, de salud, de trabajo, etc., depende de alguien o algo que lo maltrata, sin que exista una terceridad que imponga la ley. Lo que predomina en la encerrona trágica no es la angustia, con todo lo terrible que esta puede llegar a ser; predomina algo más terrible aún que la angustia: el dolor psíquico, aquel que no tiene salida, ninguna luz al final del túnel" (Ulloa, F. (2005: 1)
} 
salvaje del cuerpo de sus hijos para poder mantener la estabilidad familiar.

\section{Madres que ignoran y se rebelan}

Carmelina, la madre del relato "La sposa segreta", acaba de enviudar con dos hijas pequeñas, se nos presenta como una mujer plenamente feliz tras encontrar en Giorgio, el nuevo amor de su vida. Sin embargo, se trata de un hombre, aparentemente respetable que aprovechó su posición para abusar de las niñas Giusi y Rosaria reiteradamente, algo que consigue mediante amenazas y chantajes:

Solo te pido una cosa, amor mío: No se lo digas a nadie. Mucho menos a tu madre. El nuestro es un matrimonio secreto. Si hablas yo la mato y tú no quieres que tu madre muera ¿verdad? (Maraini, 2019: 128).

El cambio en la estructura de la familia provoca la aparición o desarrollo de conductas violentas de carácter sexual (Losada \& Jursza, 2019). Tras la muerte del padre, se produce un cambio de tipo emocional por su ausencia y por su reemplazo con el padrastro, que pasa a formar parte de la familia. Conforme avanza el relato una de las niñas se arma de valor y se atreve a contárselo a la madre. Su primera reacción es, la negación rotunda, pues está convencida de que su marido es un hombre cariñoso con ellas e incapaz de cometer un acto de tal magnitud:

"Quería decirte que me ha llevado a su cama."

"No digas tonterías, Giusi. Sabes que os quiere como un padre"

"Un padre que acosa a las hijas de su querida mujer ¿Cómo lo llamas?

"Tú estás delirando. Siempre ha sido cariñoso con vosotras. Quizás estás equivocada, pero yo lo conozco bien. No haría una cosa del estilo. Además, me ama, es mi marido Giusi, hacemos el amor continuamente, ¿qué me estás contando?"

"No quiero escuchar más estas estupideces"

"No te creo, Giusi. Tienes una fantasía demasiado desarrollada" (Maraini, 2019: 38).

Explica López (2005), que muchas veces la primera reacción de una madre es la incredulidad. Carmelina es incapaz de asumir que alguien en quien depositaba toda su confianza, y que ante ella se ha labrado esa imagen de ternura y fidelidad, sea un monstruo a sus espaldas. Probablemente la madre trate de convencerse a sí misma con el fin de protegerse del dolor que le supondría enfrentar una violencia de tal magnitud. El amor hacia su compañero se convierte en una especie de dominación muy sutil y casi invisible que forma parte de la violencia 
simbólica (Bourdieu, 2000). Cuando una madre descubre que su pareja ha violado a sus hijos experimenta sentimientos contradictorios, pues la sensación de impotencia y traición hacen que trate de buscar en su mente los motivos que condujeron al agresor a actuar de esa manera.

Giusi, ante el rechazo de su madre decide grabar uno de los encuentros con el padrastro para que su discurso tenga mayor credibilidad y así la madre se quite la venda de los ojos. Cuando esto se produce, la sensación que prevalece en ella es la sorpresa: "No lo creo pero debo creerlo" (Maraini, 2019: 141). A raíz de esa revelación la madre ayuda a la niña a denunciar a su marido.

Las consecuencias de haber sufrido ASI hicieron mella en la vida de las dos hermanas de "La sposa segreta": una de ellas murió por sobredosis y la otra dejó el hogar que compartía con su madre para vivir en una comuna, siguiendo una vida de inadaptación social. La madre, en cambio, no fue capaz a superar el dolor que habían pasado sus hijas, se quedó sola y terminó deambulando por las calles con problemas psiquiátricos.

La madre hace suya y asume la culpa de la violencia que sufrieron sus hijas, sintiéndose responsable a recaer sobre ella la culpa ancestral de las mujeres (Carvalho, 2009; Galvão, 2009; Cardoso, 2009). Carmelina siente que ha fracasado con respecto al papel tradicional de madre protectora y le invade un sentimiento de impotencia por no haber podido evitar el sufrimiento de las niñas:

Todo era culpa suya, se decía, ¿por qué no había visto lo que ocurría en su casa? ¿Por qué no lo había visto? ¿De dónde venía su ceguera materna? ¿Era posible que el amor la hubiese vuelto extraña a su propia familia? ¿Tan alejada de la realidad? (Maraini, 2019: 147).

Maraini denuncia la situación de abandono en la que quedan las madres, al no ser consideradas víctima indirectas de la violencia sexual que el padre ejerce sobre sus hijos. Por otra parte, el relato recalca la conducta social que culpabiliza siempre a las madres, sobre todo las que tienen que trabajar fuera y no están en casa para proteger a sus hijos, mientras que el maltratador, el verdadero culpable, siempre encuentra beneficio de la duda y sale bastante mejor parado y amparado por el consenso general, aunque sea condenado por la justicia.

\section{Conclusiones}

A través de las madres que Dacia Maraini nos presenta en sus relatos podemos conocer esa doble reacción en las mujeres cuyos hijos sufren abusos sexuales.

Las madres del pueblo de Bagheria y Giuseppina Bacalone, llenas de temores, son incapaces de reconocer que sus maridos ejerzan delitos sexuales contra sus hijos, pues asumen que todo lo que provenga del padre es correcto y aceptable. Augusta Bari, representa a todas esas madres que por falta de independencia económica se ven obligadas a 
aceptar que sus compañeros se aprovechen de la fragilidad de sus hijas, ya que supone para ellas una estabilidad a diferentes niveles. Otras madres, representadas por Carmelina, viven en una mentira con sus parejas que ante ellas se labran una imagen cariñosa siendo un monstruo con sus hijas.

Dacia Maraini incluye a las madres como receptoras indirectas de la violencia sexual de sus hijas/hijos. Poniendo de manifiesto, a veces, su indiferencia con el fin de personificar en ellas de forma extrema la complicidad social que existe en proteger al verdugo. Otras veces, expone las consecuencias que comporta sobre sus vidas romper con la violencia que sufren sus hijos: efectos psicológicos y físicos catastróficos, incomprensión, soledad y abandono. La escritora denuncia con ello, primero, el sistema patriarcal en el que las madres son consideradas y, a su vez se consideran ellas mismas, culpables por no haber sabido proteger a sus hijos del verdadero responsable de la violencia; segundo, la desprotección institucional que sufren por la cual muchas veces, abandonadas a su suerte, pierden el control de sus vidas.

El procedimiento narrativo a través del cual se refleja la insignificancia de las madres, su falta de consideración social, sobre todo si son amas de casa y desarrollan su vida en lo domestico, es su ausencia. En las narraciones analizadas las madres no hablan Es una manera de reflejar su posición tradicional de objeto, tanto en la familia como en la sociedad. Ese silencio impuesto con el que cargan, impide igualmente el desarrollo de una relación afectiva con los hijos, pues sus acciones están marcadas por la voluntad de sus esposos, que son quienes dirigen y deciden cómo tiene que comportarse en la familia. Por lo tanto, la madre no puede desarrollar tampoco su maternidad que queda irremediablemente dañada o anulada por la relación tóxica que mantiene con el abusador de sus hijos, que es también su marido. Los personajes de las madres, silenciosos y silenciados, en los relatos estudiados ponen en evidencia una maternidad supeditada a las directrices que marcan sus maridos en el hogar y a las costumbres o normas sociales, que las despersonalizan para convertirlas en fantasmas que asisten como espectadoras al escenario de sus propias vidas.

\section{Referencias bibliográficas:}

AmATANGelo, Susan. "La bambina e il sognatore e il mito dell'infanzia". En Bertone, M. \& Meazzi, B. (2017). Curiosa di mestiere. Saggi su Dacia Maraini. Pisa: Edizioni ETS, 2017.

ANDERLINI, Serena, MARAINI, Dacia and BARRETT, Tracy. Interview: Dacia Maraini: Prolegomena for a Feminist Dramaturgy of the Feminine, «Diacritics», Vol. 21, No. 2/3, A Feminist Miscellany, Summer - Autumn (1991): 149. 
AZAOLA, Elena. Maltrato, abuso y negligencia contra menores de edad.Secretaría de Salud. Informe Nacional sobre Violencia y Salud. México, DF SSA, 2006.

BOURDIEU, Pierre. ¿Qué significa hablar? Economía de los intercambios lingüísticos. Madrid: Akal. 1985.

CARVALHO, Quitéria Magalhães, GALVÃO, Marli Teresihna and CARDOSo, Maria Vera Lucía. Abuso sexual infantil: Percepción de las madres frente al abuso sexual de sus hijas.Revista Latino-Americana de Enfermagem,17(4), (2009): 501-506.

CÁSARES, Esther. La función de la mujer en la familia. Principales enfoques teóricos.Aposta. Revista de Ciencias Sociales,36, 1-21, 2008.

FloRENCE, Rush, The Best Kept Secret. Sexual Abuse of Children, Englewood Cliffs, Prentice-Hall, 1980.

Gabriele, Tommasina. The Pregnant Nun: Suor Attanasia and the Metaphor of Arrested Maternity in Dacia Maraini, «ltalica», Vol. 81, No. 1, Spring (2004): 65.

GalASso, Giuseppe. Gli studi di storia della famiglia e il Mezzogiono d'Italia.Mélanges de l'École française de Rome,95 (1) (1983): 149-159.

HABRLE, Tanja and Popović, Martina. il tema della violenza in buio, di Dacia Maraini.Studia Polensia,4(1), (2015): 23-31.

INTEBI, Irene. Abuso sexual infantil: en las mejores familias. Ediciones Granica SA, 2001.

IVANČIĆ, Kristina.ll rapporto madre-figlia nelle opere di Dacia Maraini, Lalla Romano e Francesca Sanvitale(Doctoral dissertation, University of Pula. Department of Interdisciplinary, Italian and Cultural Studies.), 2016.

LA LUNA, Michelangelo. Viollca, la bambina albanese di Dacia Maraini: dal racconto al testo teatrale.Italica (2015): 702-712.

LEONARDI, Vanessa. Gender and ideology in translation: do women and men translate differently. Bern: Peter Lang Publishing, 2007.

LÓPEZ, María, “¿Su mamá no la cuidó? Las madres ante el abuso sexual de su hijas" Recuperado de: http://www.envio.org.ni/articulo/3056

LOSADA, Analia Verónica and Jursza, Ivana Rosaura. Abuso sexual infantil y dinámica familiar.Revista Electrónica de Psicología Iztacala,22(3), 28032828, 2019.

MARAINI, Dacia. Un clandestino a bordo. Le donne: la metrnitànegata, il corpo segnato., Milano, Rizzoli Editore, 1996.

------. Amore rubato, Milano: BUR Rizzoli, 2019.

-----. Bagheria, Milano: BUR Rizzoli, 2004.

-----. Buio, Milano: BUR Rizzoli, 2018.

------. Voci, Milano: BUR, 2017. 
MILLET, Kate. From sexual politics: Theory of sexual politics.Feminist theory: $A$ reader (1969): 218-219.

NgozI AdICHIE, Chimamanda. Todos deberíamos ser feministas, Buenos Aires: Literatura Rondom House, 2015.

PICCHIETTI, Virginia. Relational Spaces: Daughterhood, Motherhood, and Sisterhood in Dacia Maraini's Writings and Films. London: Associated University Press, 2002.

QUINTERO, Fabiola, CORTÉS, David and GuZMÁN, Leonor. Caracterización de la violencia sexual durante la infancia y la adolescencia. Psicología Iberoamericana,22 (1), (2014): 25-33.

SINCLAIR, Caroline and MARTÍNEZ, Josefina. Culpa o responsabilidad: terapia con madres de niñas y niños que han sufrido abuso sexual.Psykhe (Santiago), 15 (2), (2006): 25-35.

ULLOA, Fernando. Sociedad y crueldad.Seminario internacional La escuela media hoy. Desafíos, debates, perspectivas. Ministerio de Educación, Ciencia y Tecnología de la Nación. Disponible en: http://www. me. gov. ar/curriform/publica/huerta_ulloa. Pdf, 2005.

Weinberg Sumeli, Grazia Maria. Invito alla lettura di Dacia Maraini. Pretoria: University of South Africa, 1993. 
Ambigua, Revista de Investigaciones sobre Género y Estudios

Culturales, n. ${ }^{\circ}$ 7, 2020, pp. 185-197. ISSN: 2386-8708 